\title{
Índice de qualidade ambiental suinícola (IQAS): Aspectos conceituais e metodológicos e aplicação
}

\author{
Adriano R. Souto ${ }^{1}$ \& Ricardo Ralisch ${ }^{2}$
}

\begin{abstract}
RESUMO
O IQAS é uma ferramenta que avalia as condições nos sistemas de produção de suínos em relação ao meio ambiente, através de indicadores com pesos para identificação, exame e avaliação das características do local, da infra-estrutura e das formas de manejo. Os sistemas de produção avaliados se encontram na bacia hidrográfica do rio Toledo, estado do Paraná. A coleta de dados através de visitas técnicas atendeu ao conjunto de indicadores do IQAS. Com as informações realizaram-se simulações, classificando-se as unidades na faixa regular, irregular e crítica. Para as propriedades de pequeno porte, as que sofreram reformas nos bebedouros, cochos basculantes, esterqueiras e na rede coletora, se classificaram na faixa regular, na qual se enquadraram, também, as que possuem equipamentos para aplicação nas culturas, responsável pelas atividades e área disponível, representando 16,13\%. Na faixa crítica, estas se encontram próximas aos recursos hídricos e residências, com esterqueiras em solo e baixa capacidade de armazenamento, com taxas de aplicação acima de $60 \mathrm{~m}^{3} \mathrm{ha}^{-1}$, além de resíduos na área, com 32,26\%. As demais unidades, 51,61\%, se enquadraram como irregular o que implica em risco de poluição das águas.
\end{abstract}

Palavras-chave: indicadores ambientais, produção de suínos, poluição das águas

\section{Swine environmental quality index (SEQI): Conceptual and methodological aspects and case studies}

\begin{abstract}
SEQI is a tool that evaluates the conditions in swine production systems in relation to environment, by using indicators with weights for identification, examination and evaluation of the characteristics of location, infrastructure and farm management procedures. The production systems evaluated in this study are located in the Toledo River basin, Paraná state, Brazil. The collection of data through technical visits met the set of SEQI indicators. With the information, simulations were performed and the units were classified in three groups: regular, irregular and critical. For small farms, the ones that reformed their water nipples, storage tanks, feeding devices and pipe installations, were classified as regular, as well as the ones that have their own equipments for applying manure, a worker responsible for the activities and available area, representing $16.13 \%$. In the critical level, $32.26 \%$ of the farms are located near water resources and housings, with manure in the ground and low storage capacity, with application rates above $60 \mathrm{~m}^{3} \mathrm{ha}^{-1}$, besides presenting residues in the area. The other units $(51.61 \%)$ were classified as irregular, which implies a risk of water pollution.
\end{abstract}

Key words: environmental indicators, swine production, water pollution

Doutorando em Agronomia - Manejo Solo e Água/UEL/IAPAR. Rod. Celso Garcia Cid, Km 375, CP 481, CEP 86001-970, Londrina, PR. Fone: (43) $3376-2000$. E-mail: adriano@iapar.br

2 Departamento de Agronomia/UEL. Rod. Celso Garcia Cid, Km 380, CP 6001. CEP 86051-990. Londrina, PR. Fone: (43) 3371-4555. E-mail: ralisch@uel.br 


\section{INTRODUÇÃO}

Os sistemas integrados de produção de suínos resultam em uma grande concentração espacial das criações em torno das agroindústrias, permitindo ganhos relacionados à economia mas gerando problemas ambientais, devido à destinação final inadequada dos dejetos (Amazonas, 1996). Os criatórios confinados constituem a base da expansão suinícola e induzem a adoção de manejo dos dejetos na forma líquida (Perdomo et al., 2001). Perdomo (2002) descreve que esta prática exige maior investimento em estrutura e equipamentos.

Ludke \& Ludke (2003a) relatam que a terminação dos suínos se dará em regiões próximas às produtoras de grãos onde o dejeto produzido será utilizado como adubo em propriedades de médio e grande porte. Thörneby et al. (1999) descrevem que os produtores rurais da Suécia que aplicavam dejetos no solo como fertilizantes orgânicos, passaram a sofrer restrições desde 1995, com o aumento do tempo exigido de permanência dos resíduos nas unidades receptoras. Para os suínos, o período passou para 10 meses e para bovinos 8 meses. Segundo Perdomo (1999) a armazenagem temporária visa do seu uso em épocas adequadas, reduzindo o potencial poluente, estabelecendo um período de 120 dias.

Quevedo (2003) salienta que, para qualquer sistema de tratamento que se implante, haverá sempre a necessidade de integrá-lo ao manejo da granja, pois em 99\% da suinocultura brasileira ocorre contribuição da chuva, com perdas de água e rações, aumentando o volume dos efluentes gerados além dos limites utilizados no dimensionamento, ocasionando baixas eficiências no tratamento dos resíduos.

Oliveira \& Parizotto (1994) empregando quantidades variáveis de chorume em três sistemas de preparo no Latossolo Roxo eutrófico (Paraná), obtiveram resultados economicamente viáveis com duas aplicações anuais de $30 \mathrm{~m}^{3} \mathrm{ha}^{-1}$ para as culturas de soja e milho e $15 \mathrm{~m}^{3} \mathrm{ha}^{-1}$ para o trigo, observando-se ainda incrementos nos teores de potássio e fósforo no solo. Esses pesquisadores constataram que quantidades anuais de $60 \mathrm{~m}^{3} \mathrm{ha}^{-1}$ provocaram indícios de acamamento no trigo, a partir do terceiro ano. Henklain et al. (1994) observaram a ocorrência da redução de infiltração de água no solo em sistema de preparo convencional e mínimo, aração e escarificador, nos quais eram ministradas diferentes quantidades de dejetos.

Parra et al. (2003) notaram, em locais com plantio direto, acréscimos no teor de fósforo de 224, 245 e 391\%, na camada de $0-10 \mathrm{~cm}$ de solo em relação ao tratamento de controle, onde foram ministradas quantidades anuais de 60 , 90 e $120 \mathrm{~m}^{3} \mathrm{ha}^{-1}$. Castro Filho et al. (2003) avaliaram, em propriedades agrícolas, em ambientes distintos e tipos de solo do Estado do Paraná, os efeitos de diferentes doses e concluíram que sua aplicação contribuiu para aumentar a produtividade das pastagens, do milho e soja, até uma taxa de $140 \mathrm{~m}^{3}$ ha-1 mas esta recomendação deve ficar vinculada às condições dos dejetos, área agrícola e riscos ambientais decorrentes desta prática de manejo.

Os produtores e nutricionistas têm como objetivo a maximização produtiva dos suínos e, sendo assim, buscam nas dietas uma suplementação em nutrientes, resultando em excessivas quantidades de N, P e K, que se encontram presentes nas fezes e urinas (Perdomo et al., 2001). Outros ingredientes necessários são o cobre e o zinco utilizados como promotor de ganho de peso com melhoria na conversão alimentar nas fases pós-desmame, crescimento e no controle de diarréias. Segundo Price et al. (2001) os sistemas de confinamento com desperdício de rações registram níveis elevados desses dois metais em seus efluentes. Embora sejam necessárias apenas em quantidades mínimas, são considerados potencialmente problemáticos, sendo crítico para o crescimento e saúde do suíno, pois sua concentração é proporcional às utilizadas nas dietas (Ludke \& Ludke, 2003b).

Os sistemas de produção de suínos devem possuir instalações que minimizem a influência dos fatores climáticos externos, como a temperatura, de forma a proporcionar conforto térmico adequado, referidas medidas podem ser aplicadas através do correto dimensionamento dos espaços físicos, da densidade de animais, da ventilação e refrigeração (Nääs, 2000). Connel et al. (2004) estudaram o rendimento e o comportamento dos suínos em função do número de animais por baia e constataram e que as maiores densidades apresentaram os piores resultados em relação ao fator de conversão de ganho de peso.

A limpeza das unidades produtivas pode ser subdividida em seca e úmida consistindo na retirada de restos da ração, do esterco, da sujeira impregnada no piso e paredes, com a utilização de pás e vassouras; a fase seguinte é a lavagem em que a demanda de água depende, basicamente, do sistema e equipamento empregados, da freqüência, da pressão hidráulica e da experiência do tratador (Perdomo, 2002). Para uma boa lavagem o consumo mínimo deve ser de $400 \mathrm{~L} \mathrm{~h}^{-1}$ e no máximo de $3.000 \mathrm{~L} \mathrm{~h}^{-1}$. A desinfecção consiste no controle e eliminação de microrganismos indesejáveis, através de processos químicos e físicos, que atuam sobre a sua estrutura e metabolismo, independente de seu estado funcional (Sesti et al., 1998).

Borja \& Moraes (2003) relatam que a construção de indicadores e índices cumpre um objetivo específico da avaliação da qualidade ambiental, não sendo a única maneira de avaliá-los, mas constituem em instrumentos que facilitam a leitura da realidade.

Objetivou-se, com este trabalho, propor uma metodologia que permita diagnosticar os sistemas de produção de suínos em relação ao meio ambiente, com base em indicadores que analisam e avaliam as condições das propriedades rurais, com a identificação dos gargalos físicos e operacionais; aqui considerados fatores que inibem as atividades relativas aos processos e produtos, buscando seu enquadramento junto à legislação.

\section{MATERIAL E MÉTODOS}

O Índice de Qualidade Ambiental Suinícola (IQAS) é um indicador agregado formado de um conjunto de indicadores primários que expressam as condições do sistema de produção de suínos em relação ao meio ambiente. Para construção 
do modelo elaborou-se uma matriz para identificação, exame e avaliação das características do local, da infra-estrutura e das formas de manejo existentes nas propriedades rurais.

As informações geradas pelos indicadores se baseavam na abrangência, importância, severidade e freqüência das ocorrências. A escala de valores utilizada para cada indicador varia de 1 a 5, relacionados com a melhor e com a pior situação. O procedimento para se calcular a matriz IQAS foi o emprego da somatória dos valores dos pesos obtidos, divididos pelo número de indicadores convertendo, desta forma, um problema complexo com múltiplos indicadores, para um outro problema, porém com um simples indicador. Os resultados obtidos são claros uma vez que, quanto mais elevada a pontuação maiores serão os investimentos de que o produtor deverá dispor para se adequar à legislação.

O primeiro conjunto se compõe de indicadores que caracterizam uma propriedade rural de suínos e sua área de influência; por exemplo, fazem parte deste bloco: porte do rebanho, sistema de coleta e tratamento, as práticas de conservação do solo e cultura onde são aplicados os dejetos, tipo de baias, distância e isolamento da área de produção em relação à residência do produtor e habitações, plano de nutrição, bovinos, lavagem e desinfecção das baias, distância dos recursos hídricos e fonte de abastecimento de água, dentre outros enquanto o segundo grupo agrega informações quanto ao posicionamento da unidade produtiva em relação à vertente, à área de preservação permanente, ao número de barracões, tipo de piso, condições das construções, estimativa do chorume produzido, formas de coleta, tratamento, tamanho da propriedade, quantidade aplicada nas culturas, estruturas utilizadas para alimentar e dessedentar os animais e profundidade do lençol freático. Os procedimentos empregados na operação do sistema compõem o terceiro grupo que, por sua vez, engloba: densidade de animais nas baias, isolamento da área de produção, período de armazenamento nas esterqueiras, vazamentos, contribuição de água de chuva, área cultivada, quantidade, freqüência e controle de aplicações nas culturas, declividade do terreno, textura do solo, desperdício de água e ração.

Determinaram-se, com a montagem da matriz IQAS em planilhas do Microsoft ${ }^{\circledR}$ Office Excel 2003, os valores limites, inferiores e superiores. Para identificação das faixas de risco ambiental, dividiu-se o intervalo numérico pela seguinte classificação: regular, irregular e crítica; para o ajuste final, aplicou-se o IQAS em unidades terminação de leitões (UTL), como se observa na escala ambiental adotada na Tabela 1.

Tabela 1. Índice de qualidade ambiental suinícola - IQAS

\begin{tabular}{cc}
\hline Faixa de risco ambiental & Intervalo do IQAS \\
Regular & $3,00-4,49$ \\
Irregular & $4,50-5,25$ \\
Crítica & $5,26-7,89$ \\
\hline
\end{tabular}

O modelo possibilitou a criação de diagramas nos quais se caracterizam as variáveis observadas (Figura 1). As amplitudes de variação de cada intervalo com os elementos avaliados, determinam os principais gargalos físicos e operaci- onais existentes na composição do sistema de produção de suínos. Os valores extremos podem ser encontrados onde não existem quaisquer cuidados com os resíduos, ou seja, em condições críticas, com alto risco de poluição. Por outro lado, por melhor que seja a situação, a própria potencialidade de geração de resíduos, os custos e problemas com o tratamento e sua disposição final, serão sempre empecilhos à preservação ambiental.

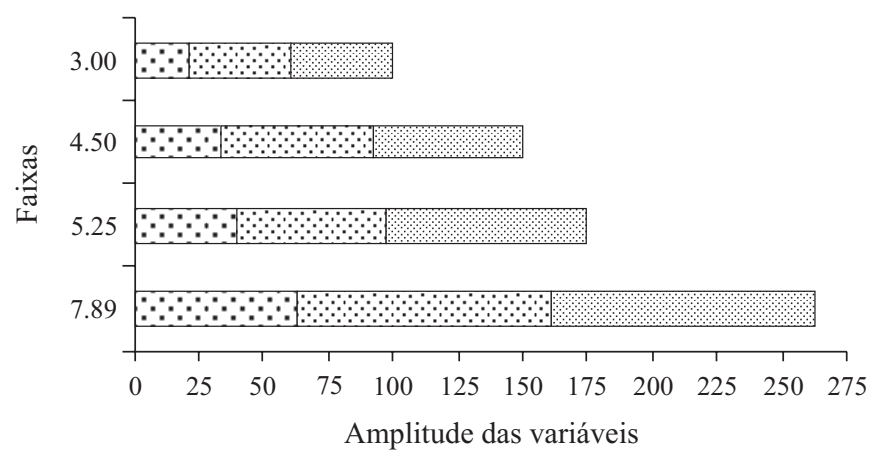

$\square$ Características do local $\because$ Infra-estrutura Formas de manejo

Figura 1. Faixas de risco do índice de qualidade ambiental suinícola - IQAS

\section{Aplicação da matriz IQAS}

O estudo de caso ora apresentado refere-se à aplicação da matriz IQAS na avaliação do sistema de produção de suínos localizados no município de Toledo, estado do Paraná. A microbacia hidrográfica do rio Toledo abrange uma área de $97 \mathrm{~km}^{2}$, inserida na sub-bacia do rio São Francisco, bacia do Paraná, entre as coordenadas geográficas $24^{\circ} 37^{\prime} 30^{\prime \prime}$ e $24^{\circ} 52^{\prime} 30^{\prime}$ ' latitude Sul e $53^{\circ} 45^{\prime}$ e $53^{\circ} 30^{\prime}$ de longitude Oeste. O curso do rio apresenta, em seu desenvolvimento, uma extensão aproximada de 27 km e, como cotas máxima e mínima, 610 e $440 \mathrm{~m}$; e se classificou no ordenamento dos canais, bacia de terceira ordem, segundo critérios introduzidos por Horton (1945) e modificados por Strahler (1957) apud Tucci et al. (1993).

A região apresenta o tipo climático Cfa, na classificação de Köppen, com as seguintes características: subtropical úmido mesotérmico com verões quentes e chuvosos, invernos com geadas pouco freqüentes, sem estação seca definida. A precipitação anual é de 1.800 mm, com evapotranspiração potencial de $1.100 \mathrm{~mm}$. A temperatura média é de $21^{\circ} \mathrm{C}$, com umidade relativa do ar oscilando entre 70 e 75\% (FUNTEC, 1992; Caviglione et al., 2000). O solo da região é classificado como Latossolo Vermelho distróférrico típico, profundo, com boa capacidade de retenção de água, aeração e permeabilidade (IAPAR, 1984; EMBRAPA, 1999); seu relevo é ondulado, constituído de colinas de topo arredondado, vertentes curtas e declives que variam entre 8 e 15\%, com altitudes entre 500 e $800 \mathrm{~m}$ e, devido a essas condições, os solos necessitam de práticas intensivas para controle da erosão. As florestas remanescentes são do tipo perenifólia, apresentando árvores de grande porte.

A atividade na bacia hidrográfica é predominantemente agrícola, composta de 240 lotes rurais, ocupada intensamente pela lavoura mecanizada de soja, trigo, milho, criação de 
gado leiteiro e de corte, suinocultura, avicultura e piscicultura (Tomm, 2001).

De outubro de 2003 a agosto de 2004, realizaram-se visitas em trinta e uma propriedades suinícolas, cujos sistemas de produção se baseavam na unidade de terminação de leitões (UTL). Para localização geográfica das unidades e estabelecimento de uma visualização dos dados cartográficos na bacia hidrográfica, utilizou-se o sistema de posicionamento global (GPS) equipamento - GARMIN 12, precisão \pm 10 m pois, segundo Cabral \& Souza (2005), o GPS permite delimitar as bacias de estudo, a localização de fontes de poluição e os limites das matas ciliares.

A análise da matriz IQAS se deu a partir dos seguintes procedimentos: a) coleta de dados primários, através do levantamento nas propriedades; b) tabulação das informações obtidas na matriz IQAS; c) análise dos resultados; d) retorno às propriedades para confirmação dos dados. As informações obtidas foram armazenadas em um banco de dados, para posterior enquadramento no IQAS.

\section{RESULTADOS E DISCUSSÃO}

A ponderação dos diversos indicadores avaliados e sua análise integrada permitiram identificar, pelo IQAS, que cinco unidades produtivas se acham na faixa regular, dezesseis na irregular e dez na crítica.

Entre as propriedades que atingiram a melhor pontuação, condição regular (IQAS < 4,50) se destacam duas: a primeira, que possui grande área para aplicação dos dejetos, boas condições estruturais da esterqueira coberta e do barracão, um funcionário para realização das atividades rotineiras; entretanto, requer ainda correções da rede primária coletora dos dejetos (IQAS $=4,23$ ); a segunda e as demais que se encontram nesta faixa sofreram intervenções no sistema de produção, como melhoria nos barracões, nas baias, piso, drenagem, hidrômetro, limpeza das passarelas, controle no desperdício de rações, além da instalação de composteiras, para uma destinação final adequada de animais mortos. Os resultados do IQAS para as UTL são apresentados na Figura 2.

É possível observar, na Figura 2, a existência de uma UTL que possui um valor do IQAS fora limite da regular e que,

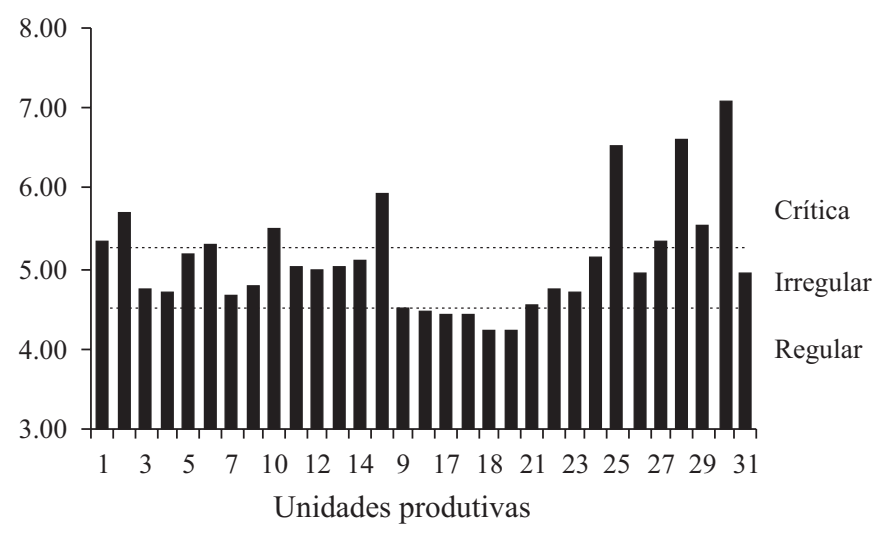

Figura 2. Enquadramento dos sistemas de produção de suínos pelo IQAS apesar das melhorias implantadas, ainda apresenta uma esterqueira em solo, o que condiciona a contaminação deste e do lençol freático (Quevedo, 2003).

Nas propriedades que se enquadraram na faixa crítica pelo IQAS, constatou-se que se encontraram localizadas a uma distância inferior a $50 \mathrm{~m}$ dos recursos hídricos e da residência de vizinhos; nessas unidades produtivas se observaram também contribuição de água de chuva na rede coletora, desperdício de água e rações, presença de esterqueiras em solo com capacidade de armazenamento inferior ao volume produzido pelo lote e ocorrência de resíduos na área, além de taxas de aplicação de chorume acima de $60 \mathrm{~m}^{3} \mathrm{ha}^{-1}$. Mohamed \& Côte (1999) ao utilizarem a lógica Fuzzy para avaliação de áreas que sofreram poluição, descreveram que para sua análise é necessário um entendimento claro de como os poluentes se encontram no local, sua concentração e distribuição espacial, seus pontos potenciais e de que maneira eles podem afetar a natureza humana.

A pior situação (IQAS $=7,08$ ) ocorreu em uma propriedade na qual 84 animais de diferentes categorias se encontravam dispostos em uma área com péssimas as condições estruturais dos barracões, cujo piso era o próprio solo, não havendo qualquer forma de coleta, tratamento nem destinação dos dejetos, nem plano de nutrição e suprimento de água; além disso, esta situação se localizava em área de preservação permanente, atuando como fonte constante de contaminação das águas do rio Toledo, em virtude da presença de resíduos no local, o que não restringe o problema a um único ponto mas à toda população abastecida por este manancial.

Para classificação do tamanho das propriedades em relação ao rebanho, o IQAS determinou que $25,81 \%$ se enquadraram como mínimas; 54,84\%, pequenas e 19,35\% médias, de acordo com a Minuta da Resolução SEMA/IAP n 31/98 (Paraná, 1998) totalizando 11.958 cabeças. No posicionamento em relação à vertente $9,70 \%$ se acham no divisor de águas; $25,80 \%$ na seção média e 64,50\% nos fundos de vale.

Com relação à distância dos recursos hídricos, o IQAS determinou que $29,00 \%$ das unidades produtivas se encontram a até 50 m; 35,50\% entre 50 e 200 m e 35,50\% acima de 200 m, condição que não atende aos critérios estabelecidos na lei federal 4.771/65, a qual institui o Novo Código Florestal (Paraná, 1996) e; para as habitações e núcleos habitacionais, $6,50 \%$ das unidades estão localizadas até $50 \mathrm{~m}$ de distância; 38,70\% entre 50 e 200 m e 54,80\% acima de $200 \mathrm{~m}$; esses resultados corroboram os valores obtidos pelo IQAS, haja vista que as unidades que indicaram as menores distâncias entre os aspectos supracitados se enquadraram na faixa crítica.

Para as unidades produtivas constatou-se que o sistema de criação é em confinamento, com o manejo dos dejetos na forma líquida, sendo que $48 \%$ das unidades apresentaram bebedouros com desperdício de água. Perdomo et al. (2001) relatam que o modelo e a operacionalidade dos bebedouros influenciam nas perdas de água, embora o consumo da chupeta seja $8 \%$ inferior ao da concha. A rede coletora observada foi de tubos e calhas fechadas com 25,80\%; calha aberta 70,97\% e chão batido $3,23 \%$. 
A principal prática de recolhimento dos dejetos é o armazenamento em esterqueiras, através do qual se levantou, pelo IQAS, que $9,70 \%$ são em lona, $41,90 \%$ em solo e $48,40 \%$ em alvenaria; com isto foi possível determinar, nas propriedades onde existem esterqueiras em alvenaria, que 53\% delas não atendiam à produção de chorume gerada pelo lote, observando-se a existência de cavas para retenção provisória dos volumes extras de dejetos. Dentre as esterqueiras em alvenaria somente três apresentavam cobertura. Oliveira \& Parizoto (1994) descrevem que isto permite melhor qualidade dos fertilizantes e menores perdas de amônia, mas dificulta o manejo por ocasião da destruição das crostas.

A entrada de água de chuva nas instalações foi também constatada, assim como vazamentos, mas não se notou quaisquer práticas de segregação na fonte dos resíduos gerados nem a presença de câmaras de fermentação nas esterqueiras. Oliveira \& Parizoto (1994) relatam que esta prática produz um fertilizante de melhor qualidade, exigindo menor volume de depósito final, sendo possível, ainda, desviar os excessos de água de lavagens e líquidos desinfetantes. Zhang \& Lei (1998) orientam que a separação das fases sólida e líquida auxilia na remoção da matéria orgânica e inorgânica.

A disposição final do chorume em culturas e a existência de arrendamentos entre os produtores rurais, é prática na região. Quanto aos equipamentos utilizados para esparramar a fração líquida, constatou-se formação de parcerias entre vizinhos, para sua aquisição; com isto, concluiu-se que não existe um controle específico nas quantidades aplicadas, principalmente nas áreas de terceiros uma vez que em 50\% das unidades produtivas as taxas de aplicação são superiores a $60 \mathrm{~m}^{3} \mathrm{ha}^{-1}$, em função da área do lote rural. Perdomo (1999) esclarece que, quando o volume gerado extrapola o limite de utilização agronômica da propriedade, deve ser tratado ou cedido a terceiros; com o exposto, conclui-se que as áreas de aplicação de dejetos não atendem aos critérios de Woliver (2004) que estabelece a distância de 66 m para residências e núcleos habitacionais.

Peréz \& Shaner (1997) afirmam que o perigo de contaminação por essa fonte está sempre presente em qualquer que seja a taxa de aplicação, especialmente quando as chuvas ocorrem logo após as aplicações. Perdomo et al. (2001) destacam que os teores de nitratos detectados no lençol freático de solos tratados com quantidades iguais a $160 \mathrm{~m}^{3} \mathrm{ha}^{-1}$, são 10 vezes superiores em relação aos sem tratamento. Ceretta et al. (2003) relatam que o $\mathrm{N}$ é um dos principais constituintes do esterco de suínos, apostando que cerca de $50 \%$ desse total está na forma mineral e, ao ser aplicado, exerce efeito imediato no crescimento das plantas; por sua vez, o escoamento superficial e a lixiviação no solo podem contaminar mananciais de água com nitrato.

Para o suprimento de água também se adotaram os critérios da SEMA/IAP n 31/98 (Paraná, 1998) que permitiram correlacionar consumo e a demanda, definindo as potencialidades de incremento no rebanho e os aspectos quanto à sua qualidade pois, segundo a CETESB (1976), é considerada crítica a distância de $45 \mathrm{~m}$ de tanques sépticos, fossas negras, estrumeiras e depósitos de lixo, situação esta também verificada. Entre as formas de captação de água utilizadas para o rebanho determinou-se na percentagem de $12,90 \%$ se abastece com poços profundos; 54,80\% do lençol freático e 32,30\% utilizam nascentes aflorantes. Pérez \& Shaner (1997) observaram que nos poços de água subterrânea da Califórnia, nos Estados Unidos, existem concentrações de nitratos e pesticidas superiores aos padrões permitidos, cuja contaminação provém da aplicação de agroquímicos e de resíduos de animais em confinamento.

Quanto ao plano de nutrição dos animais determinou-se o tipo de alimentação ora empregado, qual a cooperativa que lhes presta assistência técnica; com isto se comprova a satisfação ou não do produtor, já que o processo deve incorporar quem mora no local. As estruturas observadas para disposição de alimento aos animais foram os cochos, que podem ser em alvenaria e madeira, fixos 61,29\%; basculantes 29,03\% e automáticos 6,45\% ou, mesmo, sem nenhuma estrutura, caso esse que será disposto sobre o próprio piso 3,23\%. Para carregamento dessas unidades utilizam-se carrinhos, latas, pás e até o carregamento manual das sacas de $60 \mathrm{~kg}$, sendo que a quantidade de ração depositada nos cochos está relacionada com a fase de crescimento e com o número de leitões em cada baia.

A destinação final dos animais mortos varia entre os produtores sendo constatadas as seguintes situações: composteiras $32,30 \%$; enterrados em vala comum $45,10 \%$, queima e, muitas vezes, servido com alimento aos cachorros $22,60 \%$.

Os resultados obtidos pelo IQAS demonstram que a bacia hidrográfica do rio Toledo está sujeita, ainda, à contaminação dos recursos hídricos por dejetos de suínos, pois o valor médio obtido para todas as unidades produtivas se enquadrou na faixa irregular (IQAS $=5,10$ ), de acordo com a Figura 3.

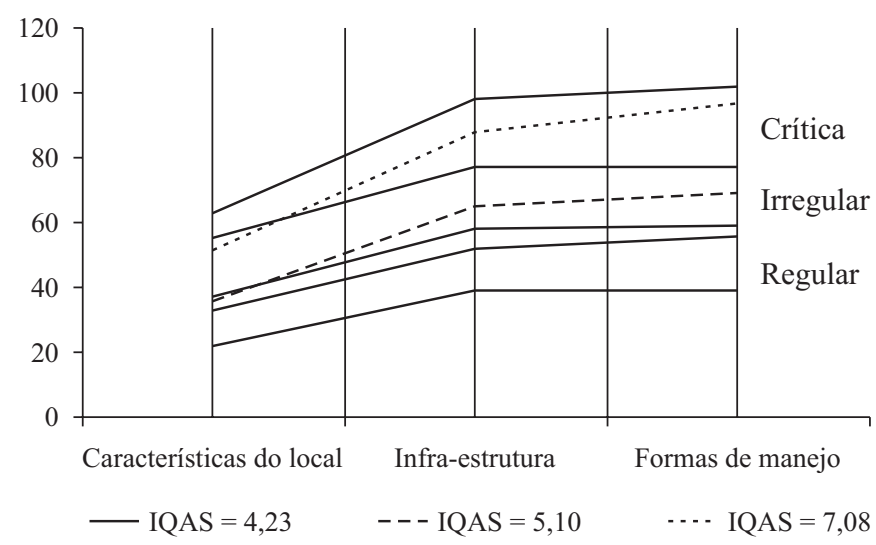

Figura 3. Classificação das unidades produtivas na matriz IQAS, Toledo, $P R, 2004$

A classificação das propriedades e a amplitude das variáveis determinadas pelo IQAS relacionaram, como pontos críticos, a infra-estrutura e as formas de manejo nas propriedades que se enquadraram como irregulares e críticas, e ser observado nas Figuras 3 e 4. A escolha de um local adequado para instalação de uma granja de suínos depende de alguns fatores, como: localização geográfica, processo de manejo e sistema de produção, entre outros (Quevedo, 2003). 


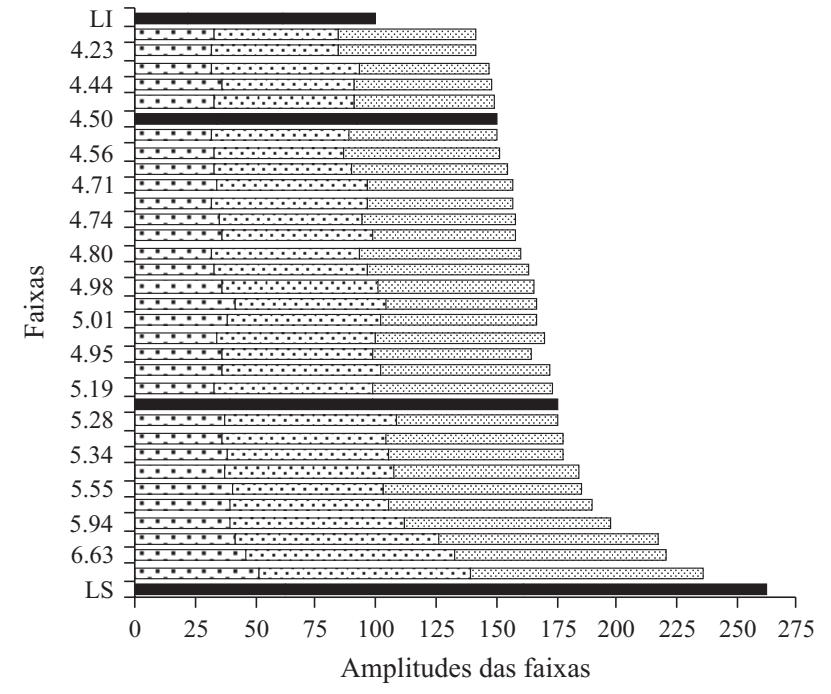

$\because$ Características do local $\because$ Infra-estrutura $\quad$ Formas de manejo
A localização das unidades produtivas e a faixa de risco ambiental do IQAS são apresentadas na Figura 5; a estimativa da produção anual e a taxa de aplicação de chorume nas Figuras 6 e 7.

O IQAS apresentou um número elevado de unidades produtivas que se enquadraram nas condições irregulares e críticas, demonstrando a necessidade da adoção de medidas imediatas de intervenção.

Os resultados do diagnóstico das propriedades rurais analisadas servirão de subsídio para orientar os produtores em relação às ações, quanto às correções a serem realizadas no sistema de produção de suínos.

A adoção de critérios para avaliação de sistemas de produção de suínos poderá ser regulamentada através do IQAS, uma vez que se trata de uma ferramenta metodológica utilizada na avaliação das condições de unidades produtivas, em relação ao meio ambiente atendendo, assim, aos padrões e normas da legislação.

A utilização do índice poderá servir de apoio dentro do

Figura 4. Faixa de risco das 31 unidades produtivas pelo IQAS, Toledo, PR, 2004

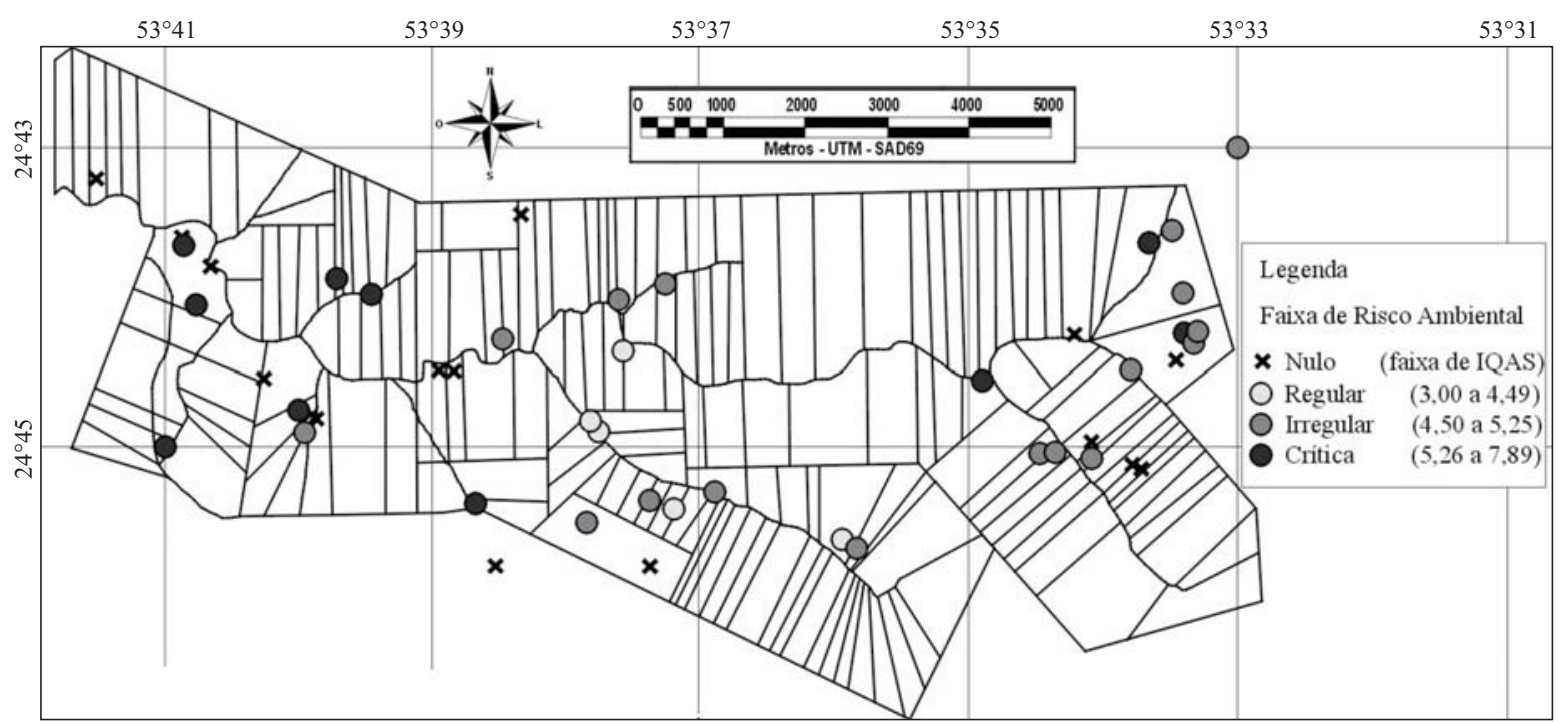

Figura 5. Localização das unidades produtivas e faixa de risco ambiental - IQAS, Toledo, PR, 2004

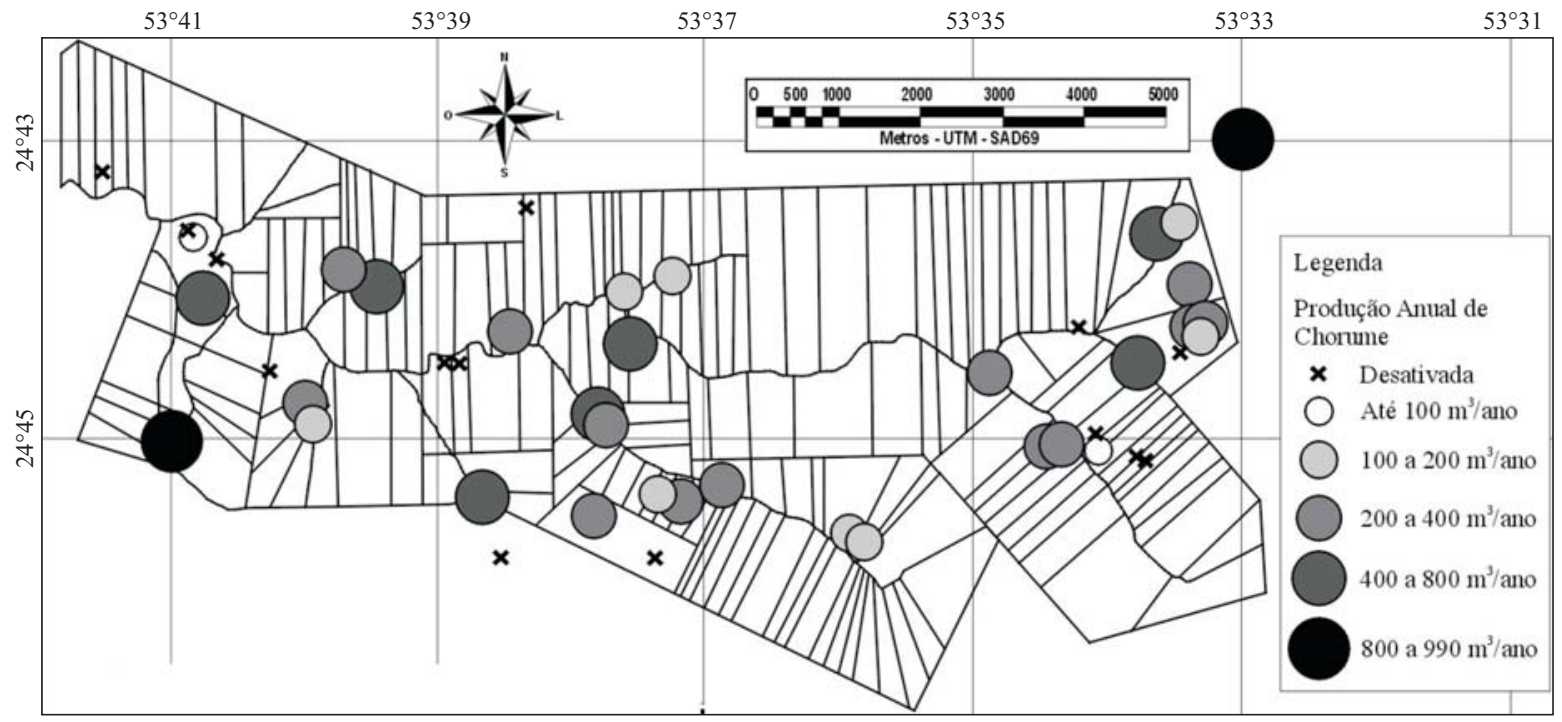

Figura 6. Localização das unidades produtivas e a estimativa da produção anual de chorume - IQAS, Toledo, PR, 2004 


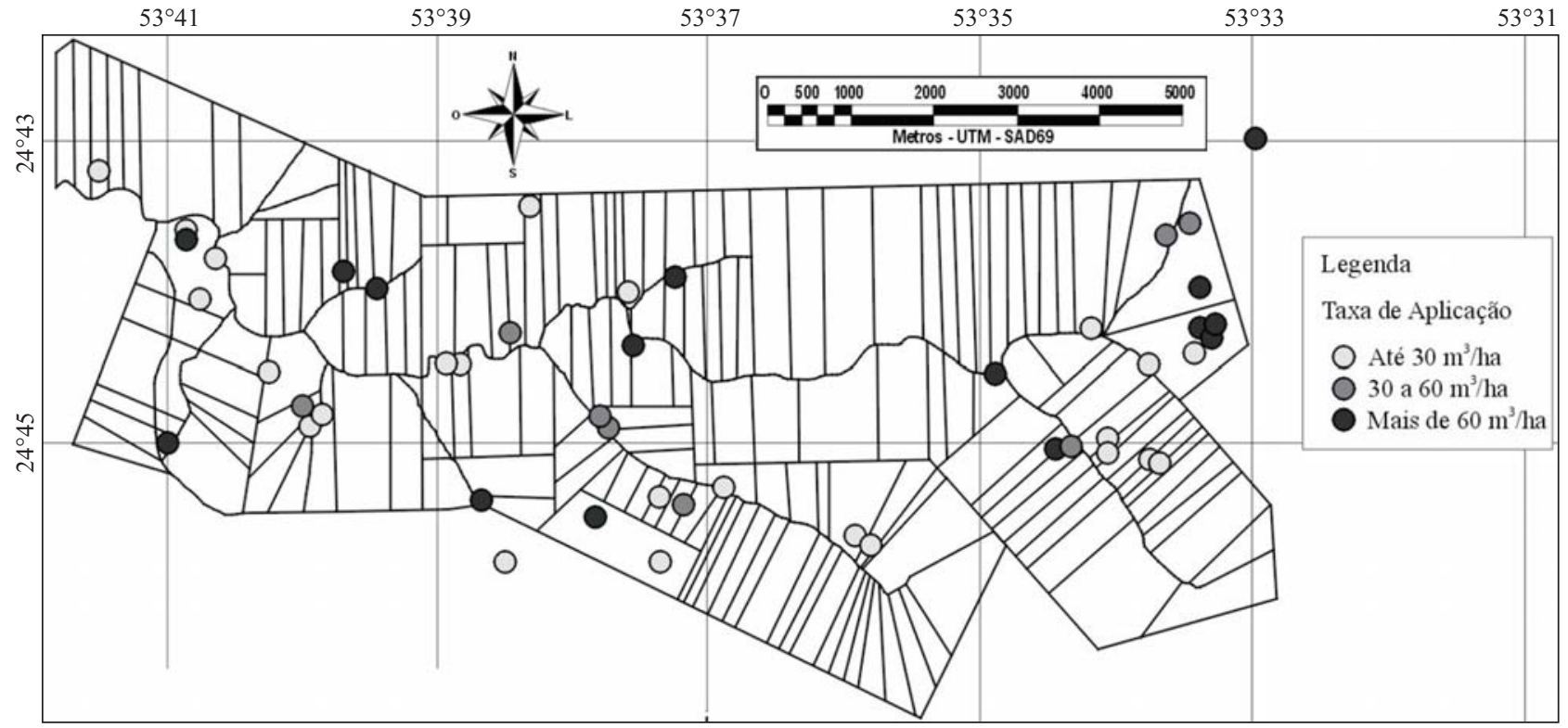

Figura 7. Localização das unidades produtivas e a taxa de aplicação de chorume (volume/área do lote) - IQAS, Toledo, PR, 2004

planejamento estratégico na definição de áreas a serem priorizadas em qualquer programa.

\section{CONCLUSÕES}

1. A utilização do IQAS é viável para avaliação rápida das condições das unidades produtivas de suínos, identificando seus principais gargalos físicos e operacionais.

2. O procedimento adotado de acordo com o método proposto é eficiente para simulação de diferentes combinações dos indicadores, que caracterizam os sistemas de produção de suínos.

3. O uso da matriz IQAS permite consistência entre as determinações quantitativas das unidades produtivas.

4. A matriz IQAS permite avaliar e comparar os diferentes sistemas de produção de suínos em uma mesma base de dados.

5. A matriz IQAS permite identificar as correções necessárias no tocante ao manejo dos dejetos visando ao seu enquadramento ou, mesmo, ao encerramento das atividades.

\section{AgRADECIMENTOS}

Os autores agradecem o precioso auxílio dos colegas Augusto Guilherme de Araújo, Alceu de Marco, João Henrique Caviglione, Jonas Galdino, Ronaldo Rossetto, Patrícia Tiemi de Paula Leite e aos produtores rurais.

\section{LITERATURA CITADA}

Amazonas, M. de C. Custos e benefícios do controle de poluição: algumas observações críticas. In: Encontro Nacional de Economia, 24, 1996. Anais... Águas de Lindóia: ANPEC, 1996, p.94-116.
Borja, P. C.; Moraes, L. R. S. Indicadores de saúde ambiental com enfoque para a área de saneamento. Parte 1 - Aspectos conceituais e metodológicos. Engenharia Sanitária e Ambiental, Rio de Janeiro, v.8, p.13-25, 2003.

Cabral, N. R. A. J.; Souza, M. P. de. Área de proteção ambiental: planejamento e gestão de paisagens protegidas. 2.ed. São Carlos: RIMA, 2005. 158p.

Castro Filho, C.; Costa, M. A. T.; Caviglione. J. H. Potencial fertilizante e alterações físicas nos solos decorrentes da utilização do chorume suíno. In: Congresso Brasileiro de Ciência do Solo, 29, 2003. Ribeirão Preto. Anais... Ribeirão Preto: SBCS, 2003. 4p.

Caviglione, J. H.; Kiihl, L. R. B.; Caramori, P. H.; Oliveira, D. Cartas climáticas do Paraná. IAPAR, Londrina, 2000. CD-Rom.

Ceretta, C. A.; Durigon, R.; Basso, J.; Barcelos, L. A. R.; Vieira, F. C. B. Características químicas de solo sob aplicação de esterco líquido de suínos em pastagem natural. Pesquisa Agropecuária Brasileira, Brasília. v.38, n.6, p.729-735, 2003.

CETESB - Companhia Estadual de Tecnologia de Saneamento Básico e de Defesa do Meio Ambiente. Técnicas de abastecimento e tratamento de água. 2.ed. v.2. São Paulo: CETESB. 1976. 550p.

Connel, N. E. O.; Beattie, V. E.; Weatherup, R. N. Influence of group size during the post-weaning period on the performance and behaviour of pigs. Livestock Production Science, Amsterdam. 2004, v.86, n.1-3, p.225-232.

EMPRAPA - Empresa Brasileira de Pesquisa Agropecuária. Centro Nacional de Pesquisa de Solos. Sistema brasileiro de classificação de solos. Brasília, 1999. 427p.

FUNTEC - Fundação para o Desenvolvimento Científico e Tecnológico de Toledo. Recuperação ambiental da bacia hidrográfica do rio Toledo. Toledo: Grafo. 1992. 87p.

Henklain, J. C.; Parra, M. S.; Hamakawa, P. J.; Oliveira, E de. Efeito do chorume de suínos sobre as propriedades hidráulicas do solo. In: Reunião Brasileira de Manejo e Conservação do Solo e da Água, 10. 1994, Florianópolis: Resumos... Florianópolis: SBCS, 1994. p.216-17. 
IAPAR - Instituto Agronômico do Paraná. Levantamento de Solos no Estado do Paraná. Londrina. EMBRAPA/SNLCS/SUDESUL/IAPAR. 1984, 791p.

Ludke, J. V.; Ludke, M. C. M. M. Preservação ambiental. Suinocultura Industrial, Porto Feliz, ed.167, n.2. p.10-13, 2003a.

Ludke, J. V.; Ludke, M. C. M. M. Produção de suínos com ênfase na preservação do ambiente. Suinocultura Industrial, Porto Feliz, ed.168, n.3, p.10-12, 2003b.

Mohamed, A. M. O.; Côte, K. Decision analysis of polluted sites - a fuzzy set approach. Waste Management, Amsterdam, v.19, p.519-533. 1999.

Nääs, I. A. A influência do meio ambiente na reprodução de porcas. In: Simpósio Internacional de Suinocultura, 5, 2000. São Paulo. Anais... Porto Feliz: Gessulli, 2000. p.142-151.

Oliveira, E. de; Parizotto, M. L. V. Características e uso de fertilizantes do esterco de suíno. Londrina: IAPAR, 1994. 24p. Circular, 83.

Paraná. Secretaria de Estado do Desenvolvimento Urbano e do Meio Ambiente. Coletânea de Legislação Ambiental. Curitiba: IAP/GTZ. 1996. p.823.

Paraná. Secretaria de Estado do Meio Ambiente e Recursos Hídricos. Minuta Resolução n. 31. Curitiba: SEMA/IAP. 1998. p.70.

Parra, M. S.; Oliveira, E. de; Costa, M. A. T.; Oliveira, E. L. de; Castro Filho, C. Alterações nos atributos químicos do solo associadas à aplicação de chorume de suínos em sistema de plantio direto. In: Congresso Brasileiro de Ciência do Solo, 29, 2003. Ribeirão Preto. Anais... Ribeirão Preto: CBCS, 2003, 3p.

Perdomo, C. C. Sugestões para o manejo, tratamento e utilização de dejetos de suínos. Instrução técnica para o suinocultor. Concórdia: Embrapa-CNPSA, 1999. 2p.

Perdomo, C. C. Custos do dejeto suíno. Suinocultura Industrial, Porto Feliz, ed.163, n.7. p.12-15, 2002.
Perdomo, C. C.; Lima, G. J. M. M.; None, S. K. Produção de suínos e meio ambiente. In: Seminário Nacional de Desenvolvimento da Suinocultura, 9, 2001. Gramado. Anais... Concórdia: Embrapa Suinos e Aves, 2001. p.8-24.

Pérez, E. G.; Shaner, W. W. Manejo integrado de cuencas: documento de referencia para los países da América Latina. Santiago, Oficina Regional de la FAO para América Latina y el Caribe. RLC/97/04-FOR-54, 1997. 542p.

Price, M. S.; Classen, J. J.; Payne, G. A. Aspergillus niger absorbs copper and zinc from swine wastewater. Bioresource Technology. Essex, v.77, n.1. p.41-49. 2001.

Quevedo, A. Sistemas de tratamento de dejetos. Suinocultura Industrial. Porto Feliz, ed.168, n.3, p.52-56, 2003.

Sesti, L.; Sobestianski, J.; Barcellos, D. E. S. N. Limpeza e desinfecção em suinocultura. Suinocultura Dinâmica. n.20. Concórdia: Embrapa-CNPSA, 1998. 15p.

Thörneby, L.; Person, K.; Trägärdh, G. Treatment of liquid effluents from dairy cattle and pigs using reserve osmosis. Journal Agriculture Engineering Research. Silsoe. v.73, p.159-170. 1999.

Tomm, I. Avaliação da qualidade da água do rio Toledo (Toledo - Paraná) através de macroinvertebrados bentônicos. Florianópolis: UFSC, 2001. 213p. Dissertação Mestrado

Tucci, E. E. M. (org.). Hidrologia, ciência e aplicação. Porto Alegre: ABRH/EDUSP. 1993. 943p.

Woliver, J. Swine waste. Methods to reduce contamination of groundwater (1997) http://www.cee.vt.edu/program_areas/ environmental/teach/gwprimers/swine/swine.htm1. 05 Out.2004.

Zhang, R. H.; Lei, F. Chemical treatamente of animal manure for solid-liquid separation. Transactions of the ASAE. St. Joseph, v.41, n.4, p.1103-1108, 1998. 